\title{
Proton Conductive Membranes Based on Poly(styrene-co-allyl alcohol) Semi-IPN
}

\author{
Felipe Augusto Moro Loureiro, Evelyn Serrano de Marins, \\ Gullit Diego Cardoso dos Anjos, Ana Maria Rocco \\ Grupo de Materiais Condutores e Energia, Escola de Química, Universidade Federal do Rio de \\ Janeiro - UFRJ \\ Robson Pacheco Pereira \\ Departamento de Engenharia Química, Instituto Militar de Engenharia - IME
}

\begin{abstract}
The optimization of fuel cell materials, particularly polymer membranes, for PEMFC has driven the development of methods and alternatives to achieve systems with more adequate properties to this application. The sulfonation of poly(styrene-co-allyl alcohol) (PSAA), using sulfonating agent:styrene ratios of 2:1, 1:1, 1:2, 1:4, 1:6, 1:8 and 1:10, was previously performed to obtain proton conductive polymer membranes. Most of those membranes exhibited solubility in water with increasing temperature and showed conductivity of approximately $10^{-5} \mathrm{~S} \mathrm{~cm}^{-1}$. In order to optimize the PSAA properties, especially decreasing its solubility, semi-IPN (SIPN) membranes are proposed in the present study. These membranes were obtained from the diglycidyl ether of bisphenol A (DGEBA), curing reactions in presence of DDS (4,4-diaminodiphenyl sulfone) and PSAA. Different DGEBA/PSAA weight ratios were employed, varying the PSAA concentration between 9 and 50\% and keeping the mass ratio of DGEBA:DDS as 1:1. The samples were characterized by FTIR and by electrochemical impedance spectroscopy. Unperturbed bands of PSAA were observed in the FTIR spectra of membranes, suggesting that chemical integrity of the polymer is maintained during the synthesis. In particular, bands involving $\mathrm{C}-\mathrm{C}$ stretching $\left(1450 \mathrm{~cm}^{-1}\right), \mathrm{C}=\mathrm{C}$ (aromatic, $\left.\sim 3030 \mathrm{~cm}^{-1}\right)$ and C-H (2818 and $2928 \mathrm{~cm}^{-1}$ ) were observed, unchanged after the synthesis. The disappearance or reduction of the intensity of the band at $916 \mathrm{~cm}^{-1}$, attributed to the DGEBA epoxy ring, is evidenced for all samples, indicating the epoxy ring opening and the DGEBA crosslinking. Conductivity of $\mathrm{H}_{3} \mathrm{PO}_{4}$ doped membranes increases with temperature, reaching $10^{-4} \mathrm{~S} \mathrm{~cm}^{-1}$.
\end{abstract}

Keywords: IPN, proton conductive membrane, copolymer, electrochemical impedance spectroscopy.

\section{Introduction}

Renewable energy sources are currently among the most active research areas due to the global climate changes and their consequences. Solar, wind and hydroelectric power plants are the most used energy sources in many countries, especially in Brazil ${ }^{[1]}$. The increasing petroleum consumption and the current concerns about climate changes have driven many researchers to the development of materials and devices for energy conversion technologies, such as photovoltaic devices and fuel cells. These devices are intended to supply power for small stationary, vehicular and mobile applications ${ }^{[2,3]}$. Among the different power sources available for electric energy conversion, fuel cells (FC) exhibit many advantages, particularly zero carbon emission, when using hydrogen as fuel ${ }^{[1]}$. FC are devices in which the chemical energy is converted into electric energy via electrocatalytic reactions and are characterized mainly by the electrolyte and fuel used, as in alkaline fuel cells (AFC); phosphoric acid fuel cells (PAFC); molten carbonate fuel cells (MCFC); solid oxide fuel cells (SOFC) and, in proton exchange membrane fuel cells (PEMFC, also known as polymer electrolyte membrane fuel cells), the polymeric membrane is responsible for the $\mathrm{H}^{+}$transport $\mathrm{t}^{[4,5]}$.
In order to allow the commercialization of FC in a large scale, a significant cost reduction must be achieved, by the optimization of materials used or the development of new ones. The optimization of polymer membranes for FC strongly depends on the knowledge of its nanostructure and proton transport mechanism, as well as the characterization of electrochemical, thermal and mechanical properties ${ }^{[6,7]}$. Among the methods aiming the optimization of polymer membranes, attention is given to the sulfonation of commercial polymers and the use of basic polymers, such as poly(imidazole) and poly(benzimidazole $)^{[8]}$. From these basic polymers, aciddoped membranes are obtained (usually with $\mathrm{H}_{3} \mathrm{PO}_{4}$ ), in which the proton transport depends on the acid concentration in the system ${ }^{[9]}$. The use of Interpenetrating Polymer Networks (IPN) as a polymeric membrane have been proposed and described in the literature, due to the possibility of free volume control associated with mechanical, thermal and chemical stability, usually exhibited by these systems ${ }^{[10]}$, although few studies have been reported. In 2011, Chikh and co workers published a review describing the application of Semiinterpenetrating Polymer Networks (SIPN) as polymeric membranes ${ }^{[7]}$. According to the IUPAC definition, while an interpenetrating polymer network (IPN) is 
A polymer comprising two or more networks which are at least partially interlaced on a molecular scale, but not covalently bonded to each other and cannot be separated unless chemical bonds are broken;

\section{a SIPN (Semi-IPN) is}

A polymer comprising one or more polymer networks and one or more linear or branched polymers characterized by the penetration on a molecular scale of at least one of the networks by at least some of the linear or branched macromolecules (Figure 1).

The combination of linear type polymer / crosslinked polymer has several advantages for IPN based membranes. First, the use of a linear or branched polymer makes the availability of starting materials of choice large and, additionally, only one chemical reaction must be carried out to obtain the material. This fact considerably reduces the occurrence of undesired side reactions between the two components as copolymerization and grafting. The availability of starting materials and the possibility of changing SIPN composition allow the tuning of optimized properties such as high ionic conductivity; mechanical, chemical and dimensional stability at high temperatures and in oxidizing/reducing environments; low fuel permeability after water or methanol uptake and good contact with the interfaces between electrodes/ electrolyte.

In the present work, semi-interpenetrating polymer network (SIPN) membranes based on the diglycidyl ether of bisphenol-A (DGEBA) crosslinked with 4,4'diaminodiphenyl-sulphone (DDS) and poly(styreneco-allyl alcohol) were obtained and characterized by FTIR, electrochemical impedance spectroscopy and scanning electronic microscopy, in a prospective study for its future application as proton conductive membrane in PEMFC.

\section{Experimental Part}

\section{Materials and samples preparation}

Cure reactions in solution were carried out in order to obtain semi-interpenetrating network (Semi-IPN) membranes from the diglycidyl ether of bisphenol-A (DGEBA), 4,4'-diaminodiphenilsulfone (DDS) and poly(styrene-co-allyl alcohol) (PSAA). PSAA (2.200 g. $\mathrm{mol}^{-1}, 20 \mathrm{~mol} \%$ AA), DGEBA and DDS were

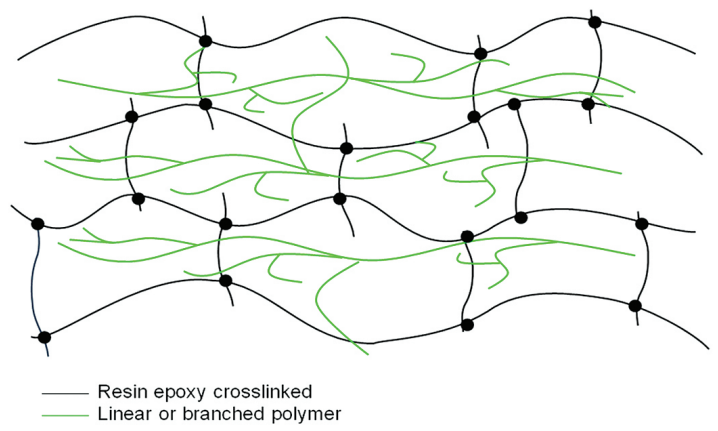

Figure 1. Squematic diagram of DGEBA-DDS/PSAA SemiIPN. purchased from Aldrich Chem. Co. and used as received. Ethanol (Aldrich, PA) was used as solvent after storage in $4 \AA$ molecular sieve.

Semi-IPN membranes containing PSAA in mass ratios of $9,17,23,29,33,38,41,44,47$ and $50 \%$ (w/w) were obtained. DGEBA and PSAA were dissolved in ethanol at $70{ }^{\circ} \mathrm{C}$ and a solution containing DDS was slowly added under constant stirring. The solutions were then heated to $130{ }^{\circ} \mathrm{C}$ under reflux until the reaction was completed, transferred to Petry dishes and dried under vacuum.

Figure 2 shows DGEBA cured with 4,4'-diaminodiphenilsulfone and poly(styrene-co-allyl alcohol) chemical structure.

\section{Characterizations}

Semi-IPN and PSAA membranes were characterized by Infrared Spectroscopy (FTIR), in a Nicolet Magna-IR 760 in the spectroscopic range between 4000 and $400 \mathrm{~cm}^{-1}$ with 128 scans per spectrum and optimized gain for all samples.

Scanning Electron Microscopy (SEM) images were obtained in a Hitachi TM1000, operating at $15 \mathrm{kV}$ and magnification of 40,80, 100 and $500 \mathrm{x}$.

Methanol uptake tests were conducted at $25{ }^{\circ} \mathrm{C}$, by immersion of the dry membranes during $24 \mathrm{~h}$ and, after removal of the solvent excess (not absorbed), weighted as $\mathrm{w}_{\mathrm{s}}$. The membranes were dried at $80{ }^{\circ} \mathrm{C}$ under vacuum and weighted as $\mathrm{w}_{0}$, from which the methanol uptake $\left(\mathrm{S}_{\%}\right)$ was calculated. The uptake values were calculated as the mean value after six experimental determinations.

$$
\mathrm{S}_{\%}=\left[100 \times\left(\mathrm{w}_{\mathrm{S}}-\mathrm{w}_{0}\right)\right] / \mathrm{w}_{0}
$$

Semi-IPN membranes were doped in $\mathrm{H}_{3} \mathrm{PO}_{4} 5 \%$ aqueous solutions during $24 \mathrm{~h}$ and dryed, in order to introduce charge carriers $\left(\mathrm{H}_{3} \mathrm{O}^{+}\right.$from dissociated acid) for proton conductivity determinations. Membranes with $0.707 \mathrm{~cm}^{2}$ were sandwiched between stainless steel electrodes for Electrochemical Impedance Spectroscopy (EIS) studies, using an Autolab PGSTAT30/FRA, with frequency between $1 \mathrm{MHz}$ and $10 \mathrm{mHz}$ at 25, 40, 50, 60 and $80{ }^{\circ} \mathrm{C}$ at $100 \%$ relative humidity, keeping the cell with the electrodes immersed in water. All EIS determinations were performed in triplicate, so the values listed represent the mean conductivity for each sample. The proton conduction resistance $(R)$ values were determined at the intercept of the EIS spectra with the real axis and the conductivity $(\sigma)$ was calculated from:

$$
\sigma=\mathrm{L} / \mathrm{A} \times \mathrm{R}
$$

In which $\mathrm{L}$ is the membrane thickness (in $\mathrm{cm}$ ) and $\mathrm{A}$ its geometrical area $\left(0.707 \mathrm{~cm}^{2}\right)$.

\section{Results and Discussion}

\section{Vibrational spectroscopy characterization}

Figure 3 depicts the FTIR spectra of Semi-IPN membranes in different spectroscopic regions, evidencing the structural changes as a function of PSAA/DGEBA ratio. 
Figures $3 \mathrm{a}$ and $\mathrm{b}$ exhibit some of the characteristic vibrational modes of PSAA, DDS and DGEBA, as well as their variation as a function of concentration in the SemiIPN membranes. The epoxy $v(\mathrm{C}-\mathrm{H})$ mode, characteristic of DGEBA, is detected at $3056 \mathrm{~cm}^{-1}$ (not shown) and, in Figure $3 \mathrm{~b}$, the band at $916 \mathrm{~cm}^{-1} \mathrm{v}$ (epoxy) is evidenced for pure DGEBA. The intensity decrease and consequent suppression of this band at $916 \mathrm{~cm}^{-1}$ is associated with the epoxy ring opening reaction and confirms the formation of a polymeric structure involving DGEBA units ${ }^{[11]}$. The epoxy resin cure reaction induces structural changes associated to the ring opening polymerization, among

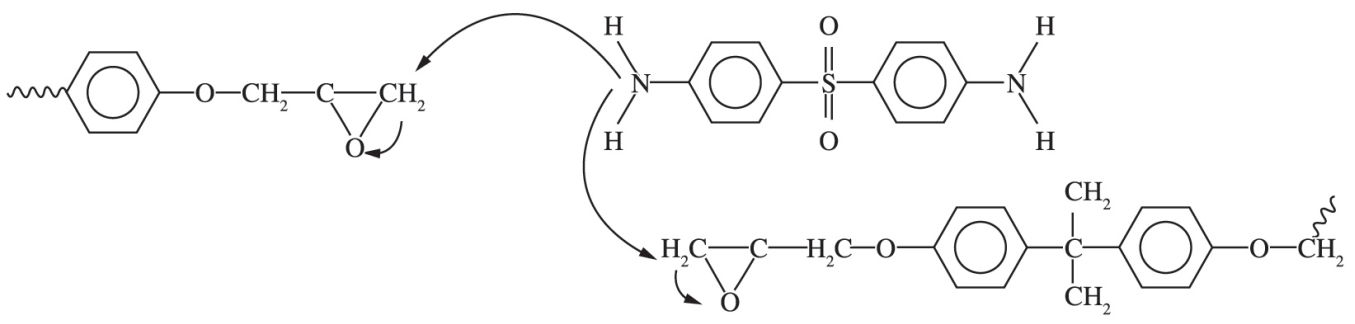<smiles>[R]Oc1ccc(C(C)(C)c2ccc(OCC(O)CN([R])C([2H])C(O)CN([R])C([2H])C(O)COc3ccc(C(C)(C)c4ccc(O[N+]([O-])O[Na])cc4)cc3)cc2)cc1</smiles>

(a)

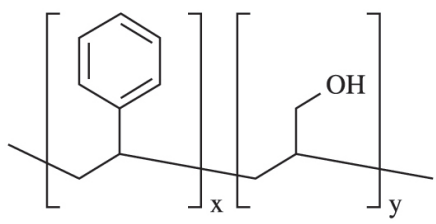

(b)

Figure 2. (a) DGEBA cured with 4,4'-diaminodiphenilsulfone, (b) poly(styrene-co-allyl alcohol) chemical structure.

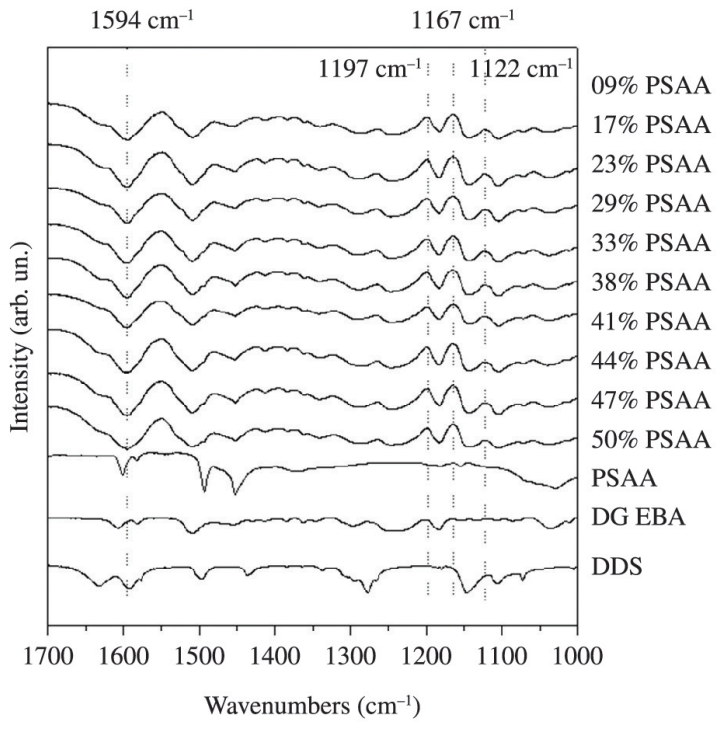

(a)

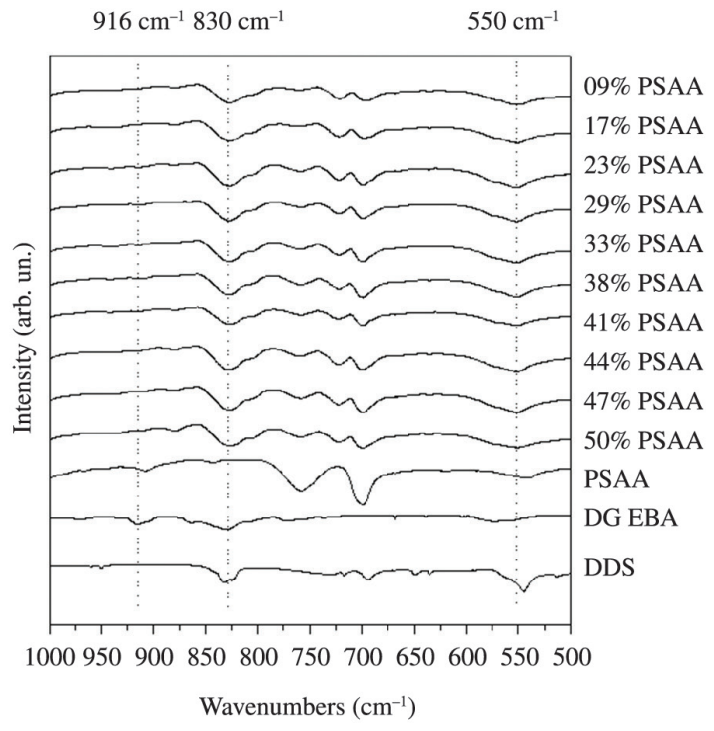

(b)

Figure 3. FTIR spectra of Semi-IPN membranes in different spectroscopic regions: (a) $1700-1000 \mathrm{~cm}^{-1}$; (b) $1000-500 \mathrm{~cm}^{-1}$. 
which the formation of hydroxyl groups, evidenced by the out-of-plane $\mathrm{OH}$ vibrational mode at $1638 \mathrm{~cm}^{-1}$. The FTIR spectra also evidence the maintenance of the PSAA chemical structure after the Semi-IPN formation, markedly the vibrational modes: C-C $\left(1450 \mathrm{~cm}^{-1}\right.$, Figure 3a); $\mathrm{C}=\mathrm{C}$ (aromatic, $\left.3030 \mathrm{~cm}^{-1}\right)$, and $\mathrm{C}-\mathrm{H}(2818$ and $2928 \mathrm{~cm}^{-1}$ ) (not shown).

The increase in PSAA concentration also evidences the increase in the $1183 \mathrm{~cm}^{-1}$ band intensity, probably associated with the formation of ether groups during the epoxy ring reaction ${ }^{[12]}$. For all the Semi-IPN membranes spectra, the epoxy ring vibrational mode is absent, evidencing the complete reaction and, consequent formation of the Semi-IPN system DGEBA/PSAA.

DDS characteristic vibrational modes are marked on the spectra represented in Figure $3 b$. The $v(\mathrm{O}=\mathrm{S}=\mathrm{O})$ band at $1149 \mathrm{~cm}^{-1}$ is observed in the Semi-IPN spectra, as well as the $v(\mathrm{C}-\mathrm{N})$, at $1183 \mathrm{~cm}^{-1}$, confirming the cure reaction involving DDS.

\section{Morphology}

Representative SEM images of Semi-IPN membranes are shown in Figure 4.

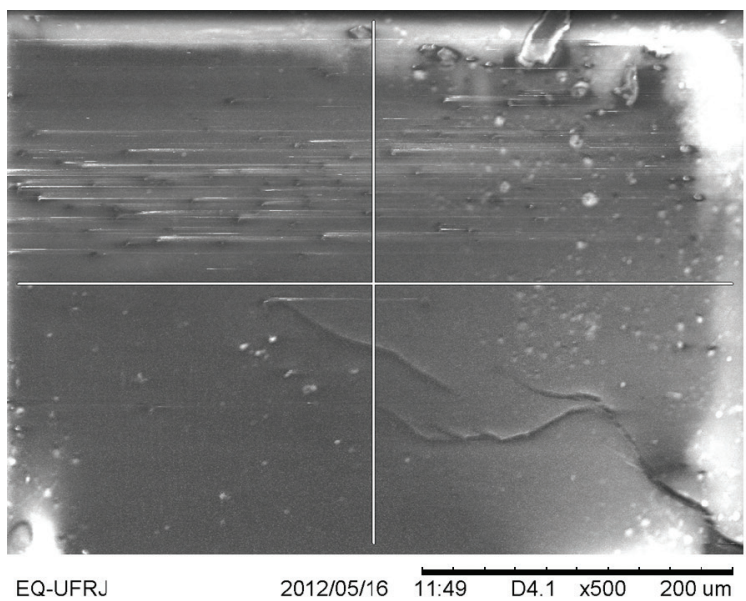

(a) $17 \%$ PSAA

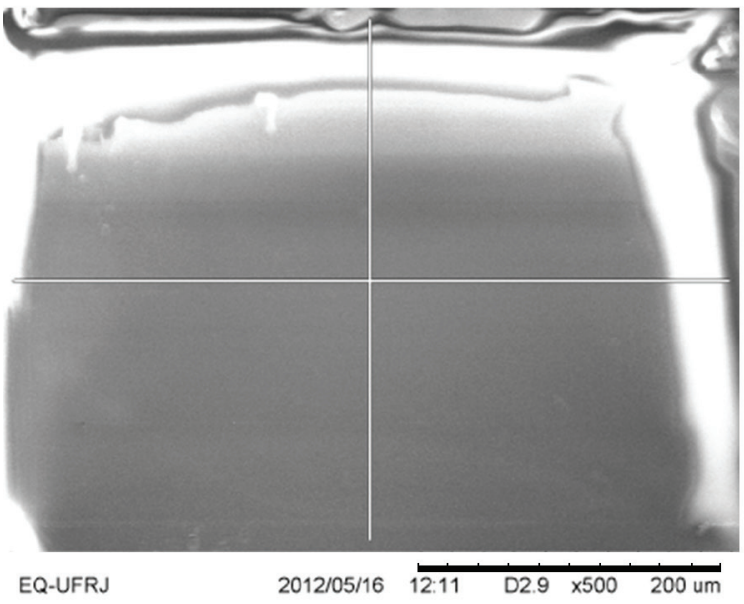

(c) $33 \%$ PSAA
As observed in Figure 4, all membranes exhibit good homogeneity up to the magnification used. The membranes containing lower PSAA concentrations (29\%) exhibited a compact and continuous morphology, closely related to the one observed for cured epoxy resins. In these samples, surface irregularities are most likely related to solvent evaporation during samples preparation.

Membranes containing 33 to $50 \%$ PSAA also exhibited good homogeneity, with surface structures detached from the continuous polymer matrix. The increase in PSAA content in the membranes induces slight variations in the surface morphology, with formation of less homogeneous structures, as observed by SEM.

Due to the continuous structure observed in SEM images and the good homogeneity detected, there is no evidence of phase separation in the system, as pointed by other authors for the characterization of IPN and blend membranes ${ }^{[13]}$. The surface continuity and compactness observed for the DGEBA/PSAA Semi-IPN membranes is key for its application in FC devices, since fuel crossover must be avoided and membrane porosity is one of the main factors influencing this characteristic.
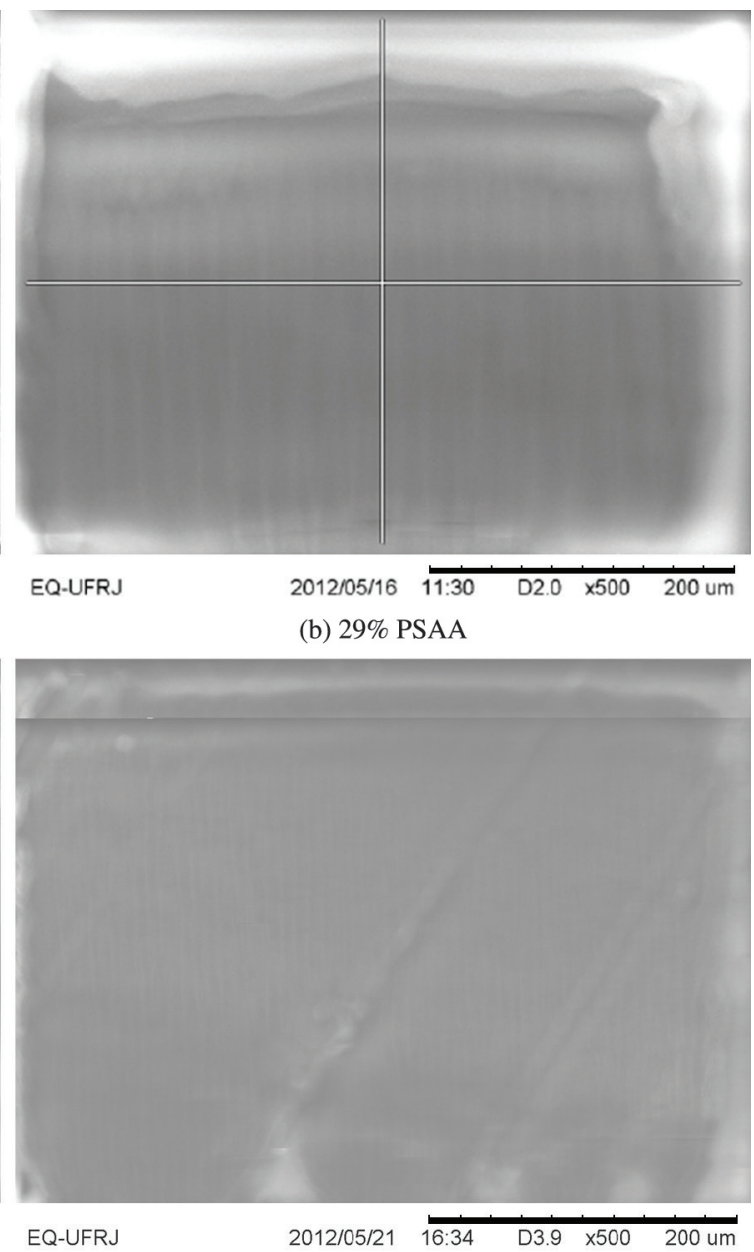

(d) $47 \%$ PSAA

Figure 4. SEM images selected Semi-IPN membranes: (a) 17\% PSAA; (b) 29\% PSAA; (c) 33\% PSAA; (d) 47\% PSAA. 


\section{Methanol uptake}

Table 1 lists the methanol uptake values for the DGEBA/PSAA Semi-IPN membranes.

Significant methanol uptake values were detected for all samples and, at this stage of development, are prohibitive for the application of such membranes in methanol direct PEMFC devices. On the other hand, its application in hydrogen-based PEMFC is not affected by methanol uptake or crossover. For these devices, in which the proton conductivity is a key property for the application, water uptake is a more adequate feature to be described. The values obtained do not exhibit a clear behavior with the PSAA content in the membranes, however, there seems to be an irregular tendency of increase in methanol uptake as the PSAA mass ratio increases in the membranes.

The SIPN studied can provide hydrogen bonds between the hydroxyl of poly(styrene-co-allyl alcohol) and ether groups of the crosslinked polymer (Figure 2) and the ratio of free hydroxyl groups to hydrogen bonded ones influences the alcohol absorption. Furthermore, membrane inhomogeneities caused by possible fluctuations in solvent evaporation speed during film formation by casting process may also influence methanol uptake by changing the agglomeration of ionic groups and the concentration of hydrophilic and hydrophobic domains in the membrane. However, measurements at different parts of a membrane exhibited only small deviations, which indicates homogeneity in the distribution of hydrophilic and hydrophobic domains. Considering that methanol uptake values were between 90 and $264 \%$, these SIPN membranes were discarded for use in direct methanol fuel cells (DMFC).

\section{Proton conductivity}

Figures 5a, c, e and $\mathrm{g}$ depict the electrochemical impedance spectra of selected DGEBA/PSAA SemiIPN membranes obtained under $100 \% \mathrm{RH}$ at different temperatures and Figures $5 \mathrm{~b}, \mathrm{~d}, \mathrm{f}$ and $\mathrm{h}$ show in detail the high frequencies region of electrochemical impedance spetra with some frequencies indicated.

The characteristic ion-conductive behavior is observed for all spectra recorded, regardless the temperature. In the high frequency region, a semicircle

Table 1. Methanol uptake values for Semi-IPN membranes.

\begin{tabular}{cc}
\hline Semi-IPN $(\%$ PSAA $)$ & Methanol uptake $(\%)$ \\
\hline 50 & $100 \pm 5$ \\
47 & $232 \pm 5$ \\
44 & $235 \pm 8$ \\
41 & $264 \pm 6$ \\
38 & $137 \pm 7$ \\
33 & $104 \pm 4$ \\
29 & $171 \pm 9$ \\
23 & $113 \pm 7$ \\
17 & $90 \pm 6$ \\
9 & $153 \pm 6$ \\
\hline
\end{tabular}

associated with the ion transport resistance is observed and, in the low frequency region, a straight line associated with the electrode/electrolyte interface capacitive effects. The utilization of stainless steel blocking electrodes induces a polarization phenomenon inside the membrane, contributing to the capacitive effects mentioned. The conductivity values calculated from the resistance obtained in each EIS spectra are listed in Table 2.

Membranes containing 17, 23, 33 and 44\% PSAA exhibited conductivity values in the order of $10^{-5} \mathrm{~S}_{\mathrm{Cm}} \mathrm{cm}^{-1}$, while those containing 29, 41, 47 and 50\% PSAA, $\sigma$ values reached $10^{-6} \mathrm{~S} . \mathrm{cm}^{-1}$. Some of the membranes exhibit a tendency of increasing conductivity with temperature, evidencing a thermally activated process.

Maximum conductivity values were obtained for the Semi-IPN membrane containing $47 \%$ PSAA at $25{ }^{\circ} \mathrm{C}$ of $(1.44 \pm 1.85) \times 10^{-4} \mathrm{~S} . c m^{-1}$ and for the one containing $38 \%$ PSAA at $60^{\circ} \mathrm{C}$, of $(2.29 \pm 0.41) \times 10^{-5} \mathrm{~S} \mathrm{~cm}^{-1}$. Considering the deviations, the membranes exhibit a mean conductivity

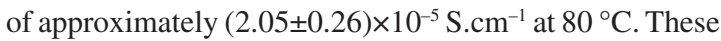
values, even inferior to others described in the literature, can be optimized by structural (chemical) modifications in the system, such as sulfonation ${ }^{[14]}$.

The temperature dependence of conductivity was studied using the Arrhenius model, and is represented in Figure 6. Semi-IPN membranes containing 17, 29, 33, 38,41 and $44 \%$ PSAA exhibited a tendency of increasing conductivity with temperature and, therefore, were studied using the Arrhenius model.

The Arrhenius model can be described by:

$$
\log \sigma=\log \mathrm{A}_{0}-\mathrm{E}_{\mathrm{a}} / \mathrm{RT}
$$

In which $A_{0}$ is the number of charge carriers; $E_{a}$ is the apparent activation energy, $\mathrm{R}$ the gas constant and $\mathrm{T}$ the temperature. The $\mathrm{E}_{\mathrm{a}}$ and $\log \mathrm{A}_{0}$ values were calculated and are listed in Table 3.

The $\mathrm{E}_{\mathrm{a}}$ values exhibit a correlation with the PSAA content in the membranes, increasing as these polymer ratio increases in the samples. All membranes exhibit $\mathrm{E}_{\mathrm{a}}<10 \mathrm{~kJ}^{\mathrm{mol}}{ }^{-1}$, suggesting a predominantly structural proton conduction mechanism (Grotthuss) ${ }^{[15]}$. Under the point-of-view of PEMFC application, it is preferable that membranes exhibit proton conduction based on both structural and vehicular mechanisms ${ }^{[16]}$. In that case, independently of the water content in the system, appreciable conductivity values can be reached, adequate for the proper PEMFC operation. Despite the indication of predominance of a structural mechanism under high hydration conditions, there is evidence of ion mobility under a PEMFC electric field, regardless the hydration

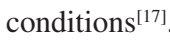

The $\log \left(\mathrm{A}_{0}\right)$ values are associated with the number of charge carriers, reflecting the number of protogenic groups, as well as their mobility. These values were found approximately constant, due to the acid doping in the membranes, carried out under the same concentration, time and temperature. 


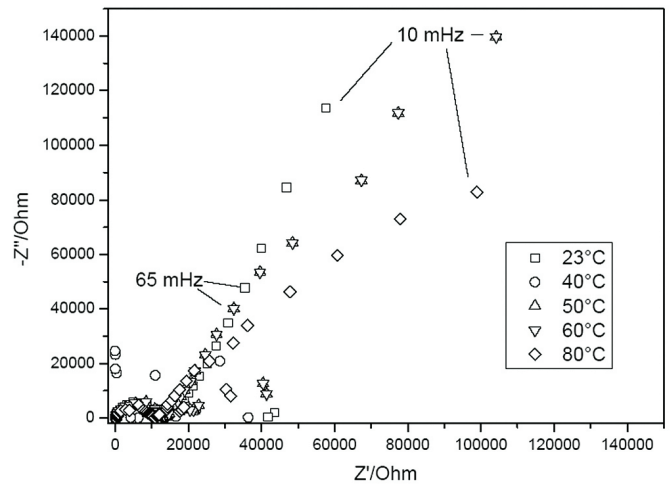

(a)

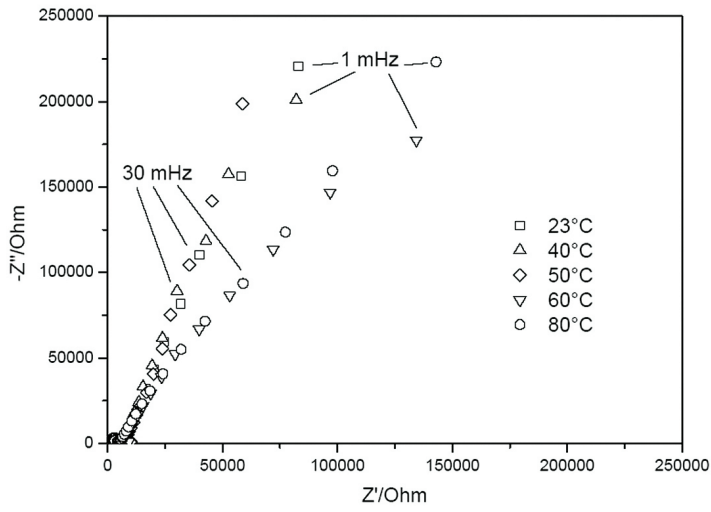

(c)

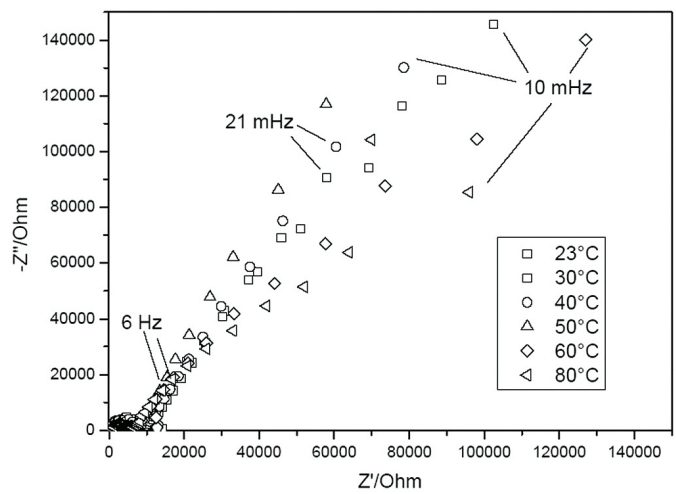

(e)

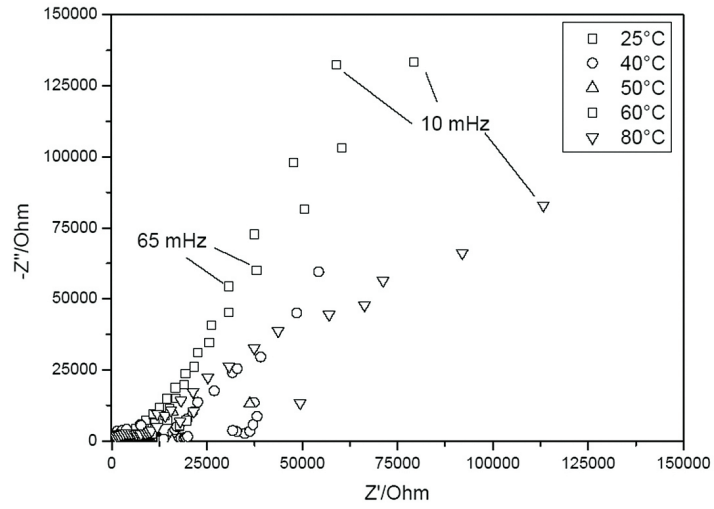

(g)

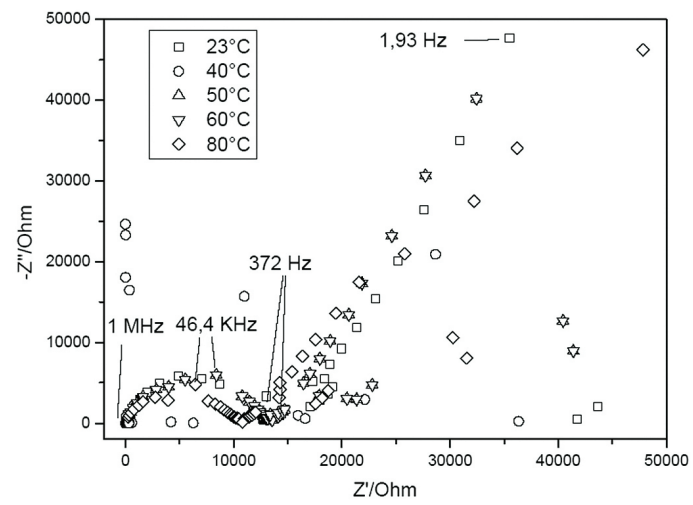

(b)

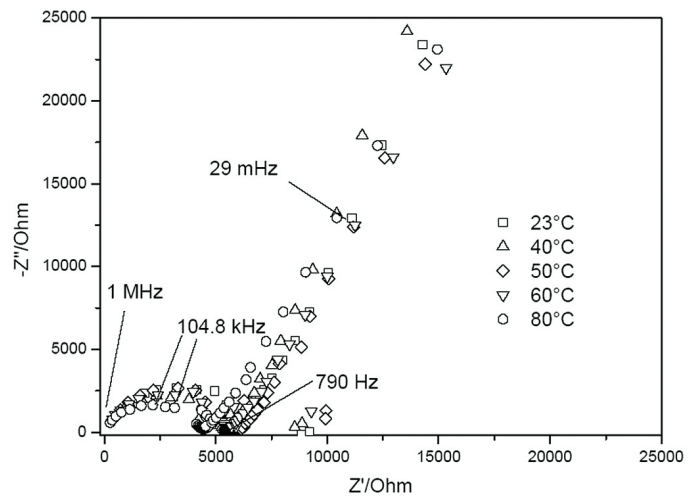

(d)

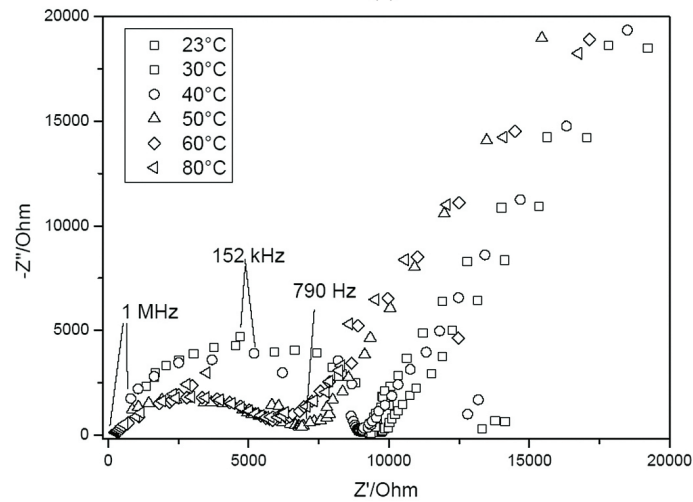

(f)

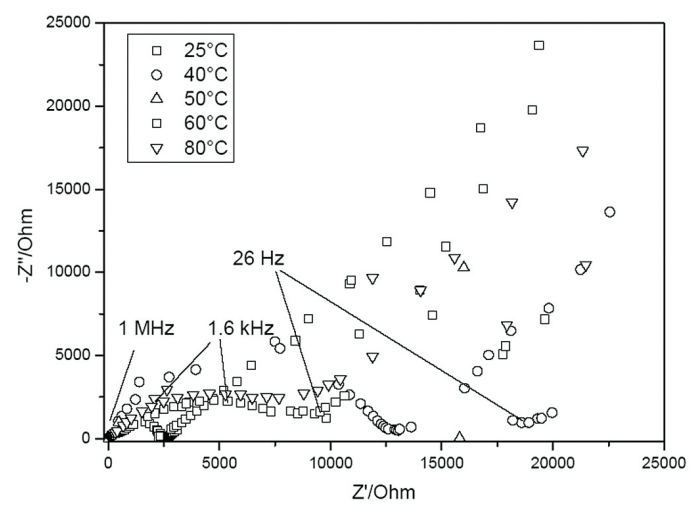

(h)

Figure 5. EIS spectra of selected Semi-IPN/ $\mathrm{H}_{3} \mathrm{PO}_{4}$ membranes: (a) 29\% PSAA; (c) 33\% PSAA; (e) 41\% PSAA; (g) 50\% PSAA. (b), (d), (f) and (h) show in detail the high frequencies region of spectra (a), (c), (e) and (g), respectively. 
Table 2. Conductivity values $\left(\mathrm{S} . \mathrm{cm}^{-1}\right)$ of SIPN/ $\mathrm{H}_{3} \mathrm{PO}_{4}$ membranes.

\begin{tabular}{cccccc}
\hline PSAA $(\%)$ & $\mathbf{2 5}{ }^{\circ} \mathbf{C}$ & $\mathbf{4 0}^{\circ} \mathbf{C}$ & $\mathbf{5 0}{ }^{\circ} \mathbf{C}$ & $\mathbf{6 0}{ }^{\circ} \mathbf{C}$ & $\mathbf{8 0}{ }^{\circ} \mathbf{C}$ \\
\hline 50 & $(2.25 \pm 0.89) \times 10^{-5}$ & $(8.30 \pm 0.42) \times 10^{-6}$ & $(7.79 \pm 0.88) \times 10^{-6}$ & $(9.01 \pm 0.78) \times 10^{-6}$ & $(1.03 \pm 0.29) \times 10^{-5}$ \\
47 & $(1.44 \pm 1.85) \times 10^{-4}$ & $(1.57 \pm 0.29) \times 10^{-6}$ & $(9.72 \pm 0.48) \times 10^{-6}$ & $(1.07 \pm 0.16) \times 10^{-6}$ & -- \\
44 & $(6.81 \pm 1.74) \times 10^{-6}$ & $(6.66 \pm 0.35) \times 10^{-6}$ & $(10.7 \pm 0.15) \times 10^{-5}$ & $(1.37 \pm 0.20) \times 10^{-5}$ & $(2.04 \pm 0.42) \times 10^{-5}$ \\
41 & $(8.66 \pm 0.40) \times 10^{-6}$ & $(1.00 \pm 0.21) \times 10^{-5}$ & $(9.67 \pm 0.77) \times 10^{-6}$ & $(1.05 \pm 0.11) \times 10^{-5}$ & $(1.19 \pm 0.69) \times 10^{-5}$ \\
38 & $(1.34 \pm 0.27) \times 10^{-5}$ & $(1.41 \pm 0.19) \times 10^{-5}$ & $(1.55 \pm 0.48) \times 10^{-5}$ & $(2.29 \pm 0.41) \times 10^{-5}$ & -- \\
33 & $(1.19 \pm 0.13) \times 10^{-5}$ & $(1.19 \pm 0.11) \times 10^{-5}$ & $(1.13 \pm 0.02) \times 10^{-5}$ & $(1.23 \pm 0.05) \times 10^{-5}$ & $(1.51 \pm 0.07) \times 10^{-5}$ \\
29 & $(4.09 \pm 0.68) \times 10^{-6}$ & $(1.00 \pm 0.38) \times 10^{-6}$ & $(4.37 \pm 1.09) \times 10^{-6}$ & $(4.84 \pm 0.54) \times 10^{-6}$ & $(5.44 \pm 0.40) \times 10^{-6}$ \\
23 & $(1.62 \pm 0.32) \times 10^{-5}$ & $(1.00 \pm 0.38) \times 10^{-5}$ & $(1.14 \pm 0.04) \times 10^{-5}$ & $(1.35 \pm 0.07) \times 10^{-5}$ & $(1.73 \pm 0.06) \times 10^{-5}$ \\
17 & $(1.51 \pm 0.28) \times 10^{-5}$ & $(1.12 \pm 0.06) \times 10^{-5}$ & $(1.21 \pm 0.11) \times 10^{-5}$ & $(1.55 \pm 0.02) \times 10^{-5}$ & $(1.95 \pm 0.07) \times 10^{-5}$ \\
\hline
\end{tabular}

Table 3. $\mathrm{E}_{\mathrm{a}}, \log \left(\mathrm{A}_{0}\right)$ and $\sigma_{\max }$ values obtained for $\mathrm{SIPN} / \mathrm{H}_{3} \mathrm{PO}_{4}$ membranes.

\begin{tabular}{cccc}
\hline PSAA $(\%)$ & $\mathbf{E}_{\mathbf{a}}\left(\mathbf{k J} \cdot \mathbf{m o l}^{-1}\right)$ & $\mathbf{l o g}\left(\mathbf{A}_{\mathbf{0}}\right)$ & $\sigma_{\text {máx }}\left(\mathbf{S . c m} \mathbf{c m}^{-1}\right)$ \\
\hline 17 & $1.78 \pm 1.91$ & $-4.16 \pm 0.71$ & $(1.95 \pm 0.07) \times 10^{-5}$ \\
29 & $2.52 \pm 1.14$ & $-4.41 \pm 0.42$ & $(5.44 \pm 0.40) \times 10^{-5}$ \\
33 & $1.54 \pm 0.79$ & $-4.33 \pm 0.29$ & $(1.51 \pm 0.07) \times 10^{-5}$ \\
38 & $1.91 \pm 0.68$ & $-4.10 \pm 0.26$ & $(2.29 \pm 0.41) \times 10^{-5}$ \\
41 & $2.07 \pm 0.35$ & $-4.22 \pm 0.13$ & $(1.19 \pm 0.69) \times 10^{-5}$ \\
44 & $8.33 \pm 1.54$ & $-1.86 \pm 0.57$ & $(2.04 \pm 0.42) \times 10^{-5}$ \\
\hline
\end{tabular}

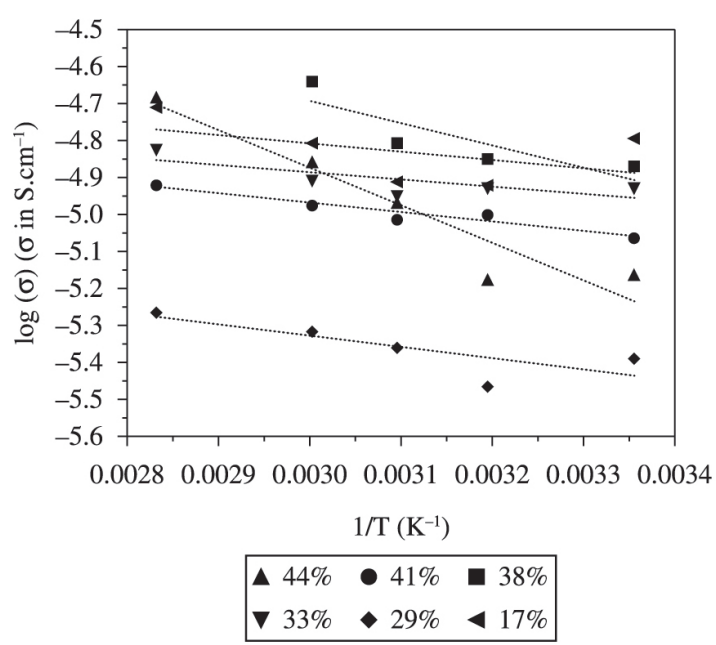

Figure 6. Conductivity dependence with temperature (Arrhenius plots) for Semi-IPN/ $\mathrm{H}_{3} \mathrm{PO}_{4}$ membranes.

\section{Conclusions}

In the present work, Semi-IPN membranes based on DGEBA and PSAA were obtained and characterized by FTIR, SEM, EIS and uptake behavior. The spectroscopic characterization evidenced the formation of a Semi-IPN structure involving DGEBA, PSAA and DDS, in which the PSAA maintained part of its chemical structure, especially in the main chain. Conductivity values of about $10^{-5} \mathrm{~S} . \mathrm{cm}^{-1}$ were obtained at $80^{\circ} \mathrm{C}$, associated with proton transport, originated from $\mathrm{H}_{3} \mathrm{PO}_{4}$ dissociation in the membranes. These conductivity values are a consequence of the molecular and macromolecular structure of the system, as well as water absorption in the membranes. The $\mathrm{E}_{\mathrm{a}}$ values calculated indicate a predominantly structural proton transport mechanism.

\section{Acknowledgements}

Authors would like to thank FAPERJ, Rede ProH2/ MCT and $\mathrm{CNPq}$ for support. Thanks also to the LabTecH2/EQ/UFRJ for the SEM images.

\section{References}

1. Silveira, J. L.; Braga, L. B.; De Souza, A. C. C.; Antunes, J. S. \& Zanati, R. - Renew. Sust. Energ. Rev., 13, p.2525 (2009). http://dx.doi.org/10.1016/j.rser.2009.06.032

2. Wang, Y.; Chen, K. S.; Mishler, J.; S. Cho, C. \& Adroher, X. C. - Appl. Energ., 88, p.981 (2011). http://dx.doi. org/10.1016/j.apenergy.2010.09.030

3. Blanco, L. T.; Loureiro, F. A. M.; Pereira, R. P. \& Rocco, A. M. - ECS Trans., 45, p.21 (2013). http://dx.doi. org/10.1149/04523.0021ecst

4. Carrete, L.; Friedrich, K. A. \& Stimming, U. - Fuel Cells, 1, p.5 (2001).

5. Smitha, B.; Sridar, S. \& Khan, A. A. - J. Membrane Sci., 259, p.10 (2005). http://dx.doi.org/10.1016/j. memsci.2005.01.035

6. Haubold, H.-G.; Vad, T.; Jungbluth, H. \& Hiller, P. - Electrochim. Acta, 46, p.1559 (2001). http://dx.doi. org/10.1016/S0013-4686(00)00753-2

7. Chikh, L.; Delhorbe, V. \& Fichet, O. - J. Membrane Sci., 368, p.1 (2011). http://dx.doi.org/10.1016/j. memsci.2010.11.020

8. Souzy, R.\&Ameduri,B.-Prog.Polym. Sci., 30, p.644(2005). http://dx.doi.org/10.1016/j.progpolymsci.2005.03.004

9. Chuang, S. W.; Hsu, S. L. C. \& Yang, M. L. - Eur. Polym. J., 44, p.2202 (2008). http://dx.doi.org/10.1016/j. eurpolymj.2008.04.021

10. Moszczynski, P.; Kalita, M.; Parzuchowsky, P.; Siekierski, M. \& Wieczorek, W. - J. Power Sources, 173, p.648 (2007). http://dx.doi.org/10.1016/j.jpowsour.2007.05.064 
11. Zhang, X. H.; Chen, S.; Min, Y. Q. \& Qi, G. R. - Polymer, 47, p.1785 (2006). http://dx.doi.org/10.1016/j. polymer.2006.01.075

12. Sanches-Cortes, S.; Berenguel, R. M.; Madejón, A. \& Pérez-Méndez, M. - Biomacromolecules, 3, p.655 (2002).

13. Okazali, Y.; Nagaoka, S. \& Kawakami, H. - J. Polym. Sci. Pol. Phys., 45, p.1325 (2007). http://dx.doi.org/10.1002/ polb. 21198

14. Silva, A. L. A.; Takase, I.; Pereira, R. P. \& Rocco, A. M. - Eur. Polym. J., 44, p.1462 (2008). http://dx.doi. org/10.1016/j.eurpolymj.2008.02.025
15. Kreuer, K. D. - J. Membrane Sci., 185, p.29 (2001). http:// dx.doi.org/10.1016/S0376-7388(00)00632-3

16. Zawodzinski, T. A.; Derouin, C.; Radzinski, S.; Sherman, R. J.; Smith, V. T.; Springer, T. E. \& Gottesfeld, S. - J. Electrochem. Soc., 140, p.1041 (1993). http://dx.doi.org/10.1149/1.2056194

17. Ren, X. M. \& Gottesfeld, S. J. - J. Electrochem. Soc., 148, p.87 (2001). http://dx.doi.org/10.1149/1.1344521

Received: 02/05/2013 Revised: 05/05/2014 Accepted: 05/14/2014 